\title{
The influence of glycemic control on the oral health of children and adolescents with diabetes mellitus type 1
}

Vera Lúcia Carneiro', Fabian Calixto Fraiz', Fernanda de Morais Ferreira', Tatiana Pegoretti Pintarelli', Ana Cristina Borges Oliveira², Margaret Cristina da Silva Boguszewsk ${ }^{3}$

\begin{abstract}
Objective: To evaluate the influence of disease control, expressed by the mean values of glycated hemoglobin $(\mathrm{HbA} 1 \mathrm{c})$, in the oral health of children and adolescents with diabetes mellitus type 1 (T1DM). Subjects and methods: A cross sectional study involving 87 children and adolescents (59 girls), $10 \pm 2.6$ years old. The participants were divided into three groups: $\mathrm{HbA} 1 \mathrm{c} \leq 8 \%, 8 \%<\mathrm{HbA} 1 \mathrm{c}$ $\leq 10 \%$ and $\mathrm{HbA} 1 \mathrm{c}>10 \%$. The duration of the disease, age and average $\mathrm{HbA} 1 \mathrm{c}$ were obtained from their medical records. Oral health was evaluated according to the following indexes: Simplified Oral Hygiene Index (OHI-S); Community Periodontal Index (CPI); Decayed, Missing or Filled Teeth Index (DMFT/dmft) for permanent and deciduous teeth; and the stimulated salivary flow rate (SSFR). Results: The median SSFR was $1.1 \mathrm{~mL} / \mathrm{min}$ in the group with $\mathrm{HbA} 1 \mathrm{c} \leq 8 \%, 0.7 \mathrm{~mL} / \mathrm{min}$ in the intermediary group and $0.6 \mathrm{~mL} / \mathrm{min}$ in the $\mathrm{HbA} 1 \mathrm{c}>10 \%$ group. A significant decrease in salivary flow was observed with an increase in HbA1c $(p=0.007)$. The DMFT/dmft and CPI indexes were higher in individuals with higher $\mathrm{HbA1c}$ values. More caries-free individuals were found in the group with $\mathrm{HbA1c}$ $\leq 8 \%$ compared to those with $\mathrm{HbA} 1 \mathrm{c}>10 \%$. The group with $\mathrm{HbA} 1 \mathrm{c}>10 \%$ exhibited more caries and bleeding gums than the other groups. $\mathrm{HbA1c}$ values in girls were higher than in boys. Conclusion: Children and adolescents with unsatisfactory glycemic control, represented by higher HbA1c concentrations, exhibited a higher frequency of caries and gingivitis, and a reduction in salivary flow. Arch Endocrinol Metab. 2015;59(6):535-40
\end{abstract}

\section{Keywords}

Oral health; dental caries; salivation; hemoglobin A, glycosylated; diabetes mellitus, type 1

\section{INTRODUCTION}

$\mathrm{T}$ he oral complications of diabetes mellitus type 1 (TIDM) include xerostomia, periodontal disease (gingivitis e periodontitis), dental abscesses, tooth loss, soft tissue lesions and burning mouth syndrome $(1,2)$. Periodontal disease is a common complication (3) and in some cases bleeding gums can be observed during early childhood. The occurrence and severity of the bleeding increase during adolescence (4-6). The duration of the illness and its metabolic control influence periodontal health. On the other hand, chronic inflammation, a characteristic of periodontal disease, may induce a certain degree of resistance to insulin, thus deteriorating metabolic control $(4,5,7)$. In similar oral hygiene conditions, individuals with poorly controlled TIDM exhibited more gingivitis, dental calculus, bone loss and gingival insertion when compared to those with good to moderate glycemic control (8-10).

Caries studies in patients with TIDM are controversial. Low caries prevalence in patients with TIDM has
1 Departamento de Estomatologia, Universidade Federal do Paraná (UFPR), Curitiba, PR, Brasil ${ }^{2}$ Departamento de Odontologia Social e Preventiva, Universidade Federal de Minas Gerais (UFMG), Belo Horizonte, MG, Brasil ${ }^{3}$ Departamento de Pediatria, UFPR, Curitiba, PR, Brasil

Correspondence to: Vera Lúcia Carneiro Rua Dario Veloso, 110, ap. 1202-B 80320-050 - Curitiba, PR, Brasil vera-carneiro@uol.com.br

Received on Mar/22/2015 Accepted on Aug/28/2015 DOI: 10.1590/2359-3997000000117 been reported in comparison with the control groups who do not have the illness (11-13). However, among the groups with TIDM, an increase in caries prevalence is observed in those with poor metabolic control $(10,14)$, and they may exhibit uncontrollable caries development in spite of extensive preventive efforts (1416). Several aspects may justify this occurrence, such as reduced salivary flow, typical in children with TIDM, even though this factor has not always been observed in relation to glycemic control $(1,15,17,18)$. The increase in salivary glucose concentration may also influence the development of dental caries $(2,19,20)$. In some cases TIDM may contribute to the severity and intensity of tooth decay, and the resulting caries may interfere with the health of a child with TIDM (21). The caries' progression may increase the risk of infection and imbalance in the glycemic control of diabetes. Moreover, the tendency of diabetic patients to develop infections caused by fungi and bacteria, and their difficulty in healing (22) are factors that may have repercussions in oral health. 
Education and preventive monitoring are necessary to avoid oral complications and thus improve these patients' quality of life $(2,13,14,23,24)$. This study was conducted with the aim of evaluating the influence of glycemic control in the oral health of a group of children and adolescents with type 1 diabetes.

\section{SUBJECTS AND METHODS}

\section{Sample selection}

Eighty-seven children and adolescents with TIDM (59 girls), 5 to 15 years of age, took part in the study. They were observed at the Pediatric Endocrinology Unit (UEP) of the Hospital de Clínicas - Universidade Federal do Paraná (HC-UFRP) in Curitiba, Brazil. Oral health evaluation took place on the date of a routine visit at the hospital. The exclusion criteria were: individuals under orthodontic treatment, recent TIDM diagnosis (less than 3 months), a lack of $\mathrm{HbAlc}$ data in their records, individuals who were sick on the date of their appointment and those with uncontrolled diseases associated with TIDM. Information regarding gender, elapsed time since TIDM diagnosis and diseases associated with TIDM were collected from medical records. Participants were divided into three groups, according to the mean values of glycated hemoglobin (HbAlc), using the results obtained over the last two years: $\mathrm{HbAlc} \leq 8 \%, 8 \%<\mathrm{HbAlc} \leq 10 \%$, and HbAlc $>10 \%$.

The HbAlc tests were performed at the same location, in the Laboratory of Chemical Analysis at the HC-UFRP. The HbAlc dosage method was immunoturbidimetric assays for $\mathrm{HbAlc}$ measure on analyzer Siemens Dimension RxL (Siemens Healthcare Diagnostics, NY, USA).

\section{Evaluation of oral conditions and salivary flow}

The oral health evaluation was conducted by only one researcher (VLC). The intra-examiner reliability was considered excellent (25), with kappa values of 0.83 and 0.94 for the indexes that evaluated gingivitis and dental caries. The oral exam was conducted in artificial light with a mouth mirror - number 5 (Prisma, São Paulo, SP, Brazil) and periodontal probe CPI (Community Periodontal Index) (Golgran, São Paulo, SP, Brazil). The mouth was divided into sextants and six index teeth were utilized (the first molar of each quadrant, the right maxillary central incisor and the left mandibular central incisor) to evaluate oral hygiene and periodontal health. Oral hygiene status was assessed using the Simplified Oral Hygiene Index (OHI-S) which is formed by the Simplified Debris Index (DI-S) and Simplified Calculus Index (CI-S) as described by Greene-Vermillion (26). In summary, the OHI-S evaluates the amount of plaque and calculus on the index teeth, and the mean was achieved by calculating the sum of the values of each aspect and dividing by 6 , with an amplitude between zero and six. Oral hygiene is considered satisfactory when the value obtained is less than or equal to one. For periodontal evaluation, the Community Periodontal Index (CPI) was utilized (27). CPI evaluates three periodontal indicators: bleeding gums, periodontal calculus and periodontal pockets (pathologically deepened gingival sulcus, caused by the destruction of the teeth supporting tissue). When examining children or adolescents under the age of 15 , only bleeding gums and calculus should be considered (27). The CPI was coded as: $0=$ healthy; $1=$ bleeding; 2 = calculus. The CPI was evaluated by summing the values of the 6 index teeth, and its amplitude is zero to twelve for this age group (27).

Dental caries experience was observed using the decayed, missing, filled teeth (DMFT) (D = Decayed, $M$ $=$ missing, $\mathrm{F}=$ filled, $\mathrm{T}=$ tooth $)$ index for permanent teeth and dmft for deciduous teeth (28). The diagnosis criteria followed the procedures proposed by the WHO (25). The DMFT index is a general indicator of the dental health status of the population and lower values in this index indicate better dental health. DMFT = zero means that the individual has not had any dental caries experience in their permanent teeth and does not have any missing or filled teeth due to a dental cavity (28). Before beginning the dental evaluation with the DMFT/dmft index, careful brushing of the teeth was performed. In this study the caries experiences were observed from data obtained from the evaluation of permanent and deciduous teeth.

Saliva was collected from all subjects between 7 a.m. and 10 a.m., just before the clinical oral examination. The child or adolescent was asked to chew on standardized piece $\left(2.0 \mathrm{~cm}\right.$ ) of paraffin (Parafilm $\mathrm{M}^{\circledast}$, Laboratory Film, Chicago, USA) and swallow the saliva produced during the first minute. During the following 5 minutes, the participant expectorated all of the saliva directly into a plastic tube. Stimulated salivary flow rate (SSFR) was evaluated by using a semi-automatic pipette (Eppendorf Research ${ }^{\circledR}$, Hamburg, Germany) and subsequently dividing the value by five in order to obtain the SSFR 
value per minute $(14,29)$. SSFR mean values of $<0.7$ $\mathrm{mL} / \mathrm{min}$ were considered as hyposalivation (30).

The study was approved by the Ethical Committee of the HC-UFRP, Curitiba, Brazil. Written informed consent was obtained from the patients and/ or parents.

\section{Statistical analysis}

The data was analyzed using the Statistical Package for the Social Sciences ${ }^{\circledR}$ software (version 15.0; SPSS Inc., Chicago, IL, USA). The calculation of frequency distribution was carried out, in addition to the Chisquare test to evaluate the relation between the variable referring to glycemic control (HbAlc; categorized in $\mathrm{HbAlc} \leq 8 \%, 8 \%<\mathrm{HbAlc} \leq 10 \%$ and HbAlc $>10 \%)$ and dentistry related variables (SSFR, DMFT, dmft, $\mathrm{CPI}$ and IHO-S) dichotomized according to theoretical references or utilizing median values. To be able to compare the value of the dentistry related variables within the groups with different $\mathrm{HbAlc}$ values, their normality was evaluated by the Kolmogorov-Smirnov test. As none of the variables met this requirement for parametric tests, the non-parametric Kruskal-Wallis test and the Mann-Whitney post-test with Bonferroni correction were utilized to make a comparison between the groups (31). The adopted significance level was $5 \%$.

\section{RESULTS}

Time elapsed since TIDM diagnosis was less than one year in $15 \%$ of the patients, between 1 to 3 years in $16 \%$ and over 3 years in $69 \%$. Mean age was $10.7 \pm 2.6$ years (range, $5-15$ years). Eleven patients (13\%) presented HbAlc $\leq 8 \%, 45$ patients $(52 \%) 8 \%<$ HbAlc $\leq 10 \%$, and 31 patients $(35 \%)$ had HbAlc $>10 \%$.

Table 1 shows the frequencies of individuals with TIDM according to sex, age and relation to the mean values of glycated hemoglobin. A higher percentage of boys were found in the HbAlc $\leq 8 \%$ group than girls ( $\mathrm{p}$ $=0.025)$. Thirty-eight individuals $(44 \%)$ were younger than 10 years of age. $80 \%$ of the group came to the appointment accompanied by their mothers.

Table 2 shows the frequencies of oral hygiene, gingival bleeding after probing, dental caries experience and hyposalivation, according to the mean values of glycated hemoglobin. Oral hygiene was considered satisfactory in 52 individuals (60\%), but all of the individuals exhibited satisfactory or regular oral hygiene. No individuals had poor or very poor oral hygiene according to OHI-S. Gingival bleeding on probing was dichotomized using the median value (IPC $<4$ e IPC $\geq 4$ ), with a significant difference between the groups $(\mathrm{p}=0.043)$. Caries experience in permanent teeth also presented significant differences $(\mathrm{p}=0.013)$. Children with DMFT $\geq 1$ exhibited high mean HbAlc values. To observe the experience of caries in subjects with mixed dentition, DMFT and dmft index are summed. Individuals with zero have no caries experience. In this case, the result was not significant $(\mathrm{p}=0.730)$. Hyposalivation was less frequent in the group with $\mathrm{HbAlc} \leq 8 \%(\mathrm{p}=0.003)$.

Table 1. Characteristics of children and adolescents with T1DM according to glycated hemoglobin values $(n=87)$

\begin{tabular}{|c|c|c|c|c|}
\hline \multirow{2}{*}{ Covariates } & \multicolumn{3}{|c|}{ Glycated hemoglobin } & \multirow{2}{*}{ P-value* } \\
\hline & $\leq 8 \% \mathrm{n}(\%)$ & $\begin{array}{l}>8 \% \text { to } \leq \\
10 \% \text { n (\%) }\end{array}$ & $\begin{array}{c}>10 \% n \\
(\%)\end{array}$ & \\
\hline \multicolumn{5}{|l|}{ Sex } \\
\hline Male & 8 (73) & $12(27)$ & $8(26)$ & \multirow{2}{*}{0.025} \\
\hline Female & $3(27)$ & $33(73)$ & $23(74)$ & \\
\hline \multicolumn{5}{|l|}{ Age } \\
\hline $5-10$ years & 7 (64) & $21(47)$ & $10(32)$ & \multirow{2}{*}{0.060} \\
\hline $11-15$ years & $4(36)$ & $24(53)$ & $21(68)$ & \\
\hline Total & $11(100 \%)$ & 45 (100\%) & 31 (100\%) & \\
\hline
\end{tabular}

${ }^{*}$ Chi-square test. Significant results at level $5 \%(\alpha=0.05)$ marked in bold.

Table 2. Oral findings in children and adolescents with T1DM according to glycated hemoglobin values $(n=87)$

\begin{tabular}{|c|c|c|c|c|}
\hline \multirow{2}{*}{ Covariates } & \multicolumn{3}{|c|}{ Glycated hemoglobin } & \multirow{2}{*}{ P-value* } \\
\hline & $\begin{array}{c}\leq 8 \% n \\
(\%)\end{array}$ & $\begin{array}{l}>8 \% \text { to } \leq \\
10 \% \text { n (\%) }\end{array}$ & $\begin{array}{c}>10 \% n \\
(\%)\end{array}$ & \\
\hline \multicolumn{5}{|l|}{ Oral hygiene } \\
\hline Satisfactory & $5(45)$ & $31(69)$ & $16(52)$ & \multirow[t]{2}{*}{0.752} \\
\hline Regular & $6(55)$ & $14(31)$ & $15(48)$ & \\
\hline \multicolumn{5}{|c|}{ Gingival bleeding after probe } \\
\hline $\mathrm{CPI}<4$ & $7(70)$ & $20(44)$ & $10(32)$ & \multirow{2}{*}{0.043} \\
\hline $\mathrm{CPI} \geq 4$ & $3(30)$ & $25(56)$ & 21 (68) & \\
\hline \multicolumn{5}{|c|}{ Caries experience in permanent teeth } \\
\hline $\mathrm{DMFT}=0$ & $8(73)$ & $19(45)$ & $9(29)$ & \multirow{2}{*}{0.013} \\
\hline $\mathrm{DMFT} \geq 1$ & $3(27)$ & $23(55)$ & $22(71)$ & \\
\hline \multicolumn{5}{|c|}{ Caries experience } \\
\hline $\mathrm{DMFT} / \mathrm{dmft}=0$ & $2(25)$ & $11(23)$ & $5(16)$ & \multirow[t]{2}{*}{0.730} \\
\hline $\mathrm{DMFT} / \mathrm{dmft} \geq 1$ & $6(75)$ & $37(77)$ & $26(84)$ & \\
\hline \multicolumn{5}{|l|}{ Hyposalivation } \\
\hline Absent & $9(82)$ & $23(51)$ & $9(30)$ & \multirow{2}{*}{0.003} \\
\hline Present & $2(18)$ & $22(49)$ & $21(70)$ & \\
\hline Total & $11(100 \%)$ & $45(100 \%)$ & $31(100 \%)$ & \\
\hline
\end{tabular}

${ }^{*}$ Chi-square test. Significant results at level $5 \%(a=0.05)$ marked in bold. One individual without CPI and hyposalivation registered; Three DMFT not registered. 
Table 3 presents the results of the oral health indicators according to mean values of glycated hemoglobin. A significant difference in the CPI values was found between groups $\mathrm{HbAlc} \leq 8 \%($ mean $=2.7$; median $=$ $3)$ and $\mathrm{HbAlc}>10 \%($ mean $=4.2 ;$ median $=4)(\mathrm{p}=$ 0.038 ).

The DMFT index was higher when the HbAlc values increased. A significant difference in the DMFT values was found between groups with $\mathrm{HbAlc} \leq 8 \%$ $($ mean $=0.8 ;$ median $=0)$ and the group with HbAlc $>10 \%($ mean $=2.4 ;$ median $=2 ;$ Table $2 ; \mathrm{p}=0.026)$. Figure 1 shows DMFT results according to the mean values of HbAlc. The association of glycemic control and dental caries presence was visible.

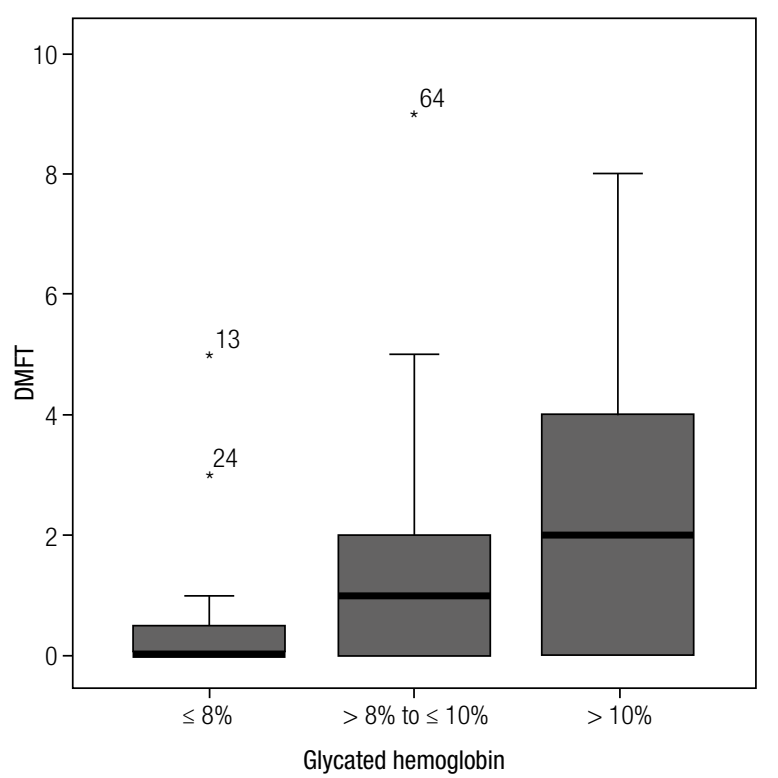

Figure 1. DMFT results according to glycated hemoglobin in children and adolescents with T1DM $(n=87)$. DMFT: Decayed, Missing, Filled Teeth.
Regarding SSFR, a significant difference in the salivary flow was found between $\mathrm{HbAlc} \leq 8 \%$ \{mean $=1.2$; median $=1.1(0.3-2.1)\}$ and the remaining groups $(\mathrm{p}=$ $0.007)$. There was no statistical difference in SSFR between the group which had $8 \%<\mathrm{HbAlc} \leq 10 \%$ and the group which had HbAlc $>10 \%$. However, both groups presented hyposalivation values $(<0.7 \mathrm{~mL} / \mathrm{min})$.

\section{DISCUSSION}

The current study was developed to evaluate the influence of the quality of diabetes control, verified through HbAlc levels, on the oral health of children and adolescents with TIDM. The results demonstrated that oral health indicators were influenced by disease control. In the groups with higher HbAlc concentration, a decrease in salivary flow, an increase in bleeding gums and dental cavities in permanent teeth were observed.

Maintaining glycemic control in children and adolescents with TIDM is a complex task that demands integrated action between the individuals with TIDM, the responsible adults and the health care providers that assist these individuals (32). In this study, it could be observed that most of the children and adolescents ( $80 \%$ of the sample) come to their regular appointments at the UEP with their mothers. Dental care should become a part of a multidisciplinary form of assistance granted to people with TIDM, and educational preventive efforts to guide the patients and the responsible adults must be increased.

Regarding gender, significantly more girls in the groups with less adequate disease control $(8 \%<\mathrm{HbAl}$

Table 3. Oral health evaluation according to glycated hemoglobin in children and adolescents with T1DM $(n=87)$

\begin{tabular}{|c|c|c|c|c|c|c|c|c|c|c|}
\hline \multirow[b]{3}{*}{ CCPI } & \multicolumn{9}{|c|}{ Glycated hemoglobin } & \multirow[t]{3}{*}{ P-value* } \\
\hline & \multicolumn{3}{|c|}{$\leq 8 \%(n=10)$} & \multicolumn{3}{|c|}{$>8 \%$ to $\leq 10 \%(n=45)$} & \multicolumn{3}{|c|}{$>10 \%(n=31)$} & \\
\hline & Mean & Median & Min-Max & Mean & Median & Min-Max & Mean & Median & Min-Max & \\
\hline & 2.7 & $3^{\mathrm{a}}$ & $0-5$ & 3.6 & $4^{\mathrm{ab}}$ & $1-7$ & 4.2 & $4^{b}$ & $0-9$ & 0.038 \\
\hline \multirow{3}{*}{ DMFT } & \multicolumn{3}{|c|}{$\leq 8 \%(n=11)$} & \multicolumn{3}{|c|}{$>8 \%$ to $\leq 10 \%(n=42)$} & \multicolumn{3}{|c|}{$>10 \%(n=31)$} & \\
\hline & Mean & Median & Min-Max & Mean & Median & Min-Max & Mean & Median & Min-Max & \\
\hline & 0.8 & $0^{\mathrm{a}}$ & $0-5$ & 1.4 & $1^{\mathrm{ab}}$ & $0-9$ & 2.4 & $2^{b}$ & $0-8$ & 0.026 \\
\hline \multirow{3}{*}{ SSFR } & \multicolumn{3}{|c|}{$\leq 8 \%(n=11)$} & \multicolumn{3}{|c|}{$>8 \%$ to $\leq 10 \%(n=43)$} & \multicolumn{3}{|c|}{$>10 \%(n=29)$} & \\
\hline & Mean & Median & Min-Max & Mean & Median & Min-Max & Mean & Median & Min-Max & \\
\hline & 1.2 & $1.1^{\mathrm{a}}$ & $0.3-2.4$ & 0.7 & $0.7^{\mathrm{b}}$ & $0.1-2.1$ & 0.6 & $0.6^{b}$ & $0.1-1.8$ & 0.007 \\
\hline
\end{tabular}

* Kruskal-Wallis test. Significant statistical differences $(\alpha=0.05)$ marked in bold.

Different letters indicate significant statistical differences in a clinical index between glycated hemoglobin groups into the line (post-test Mann-Whitney with Bonferroni correction).

CPI: Community Periodontal Index; DMFT: Decayed Missing Filled Teeth Index; SSFR: Stimulated Salivary Flow Rate. 
$\leq 10 \%$ and $\mathrm{HbAlc}>10 \%)$ were observed, and there were more boys in the HbAlc $\leq 8 \%$ group. No study that demonstrates significant differences between genders and glycemic control in TIDM could be found.

The results of this study reinforce the idea that there is an early onset of gingival alteration in children and adolescents with TIDM. Usually, bleeding on probing indicates that there is a gingival alteration called gingivitis. This situation may be related to poor oral hygiene and the presence of pathogenic microorganisms. In the current study, oral hygiene was considered adequate in over half of the group that was studied, and it was not associated with HbAlc levels. Also, the tendency to develop dental calculus described by Siudikiène and cols. (8) was not observed. These authors demonstrated that, in spite of having the same hygiene habits, individuals aged between 10 and 15 years with TIDM had a higher tendency to develop dental calculus and gingivitis than non-diabetic individuals (8). In that research study, the patients were divided into 2 subgroups, one with better control ( $\mathrm{HbAlc} \leq 8.9 \%)$ and other with less adequate control (HbAlc $\geq 9.0 \%$ ). The HbAlc group $\geq 9.0 \%$ presented higher mean values in the gingival, plaque and calculus indexes. These findings reinforce that, independent of satisfactory oral hygiene, individuals with diabetes, more precisely those with less adequate disease control, exhibit a higher risk of gingivitis.

Higher CPI values were observed in the groups with the highest HbAlc levels. CPI was lower in the group with $\mathrm{HbAlc} \leq 8 \%$ when compared with the group with HbAlc $>10 \%$, thus indicating that better glycemic control could contribute to the prevention of gingivitis. This result agrees with studies that demonstrate that gingival health is influenced by glycemic control $(5,7,13,33)$. Not all cases of bleeding gums may evolve to periodontitis. It is known however, that basic oral hygiene habits are vital for maintaining periodontal health. Despite the fact that adolescents usually have some knowledge of the association between diabetes and periodontal disease, bleeding gums are not always noticed by children and adolescents with TIDM (17). It was observed that the bleeding did not influence tooth brushing frequency or dental floss use for people in this age group (6).

The current study demonstrated an association between mean $\mathrm{HbAlc}$ values and caries prevalence. A higher percentage of children and adolescents who were caries-free in their permanent teeth $(\mathrm{DMFT}=0)$ in the groups with lower $\mathrm{HbAlc}$ values were observed, as well as an increase in caries frequency associated with those having higher HbAlc levels. A study developed in the same hospital, with another group, older than those in this study (14-19 years), did not show an association between poor metabolic control and dental caries. The sample size (51 adolescents) may have interfered in the results (13).

These results agree with other studies that have evaluated caries and HbAlc levels (14-16). Among these, a study by Twetman and cols. (14) observed a higher level of development of dental caries in individuals with TIDM aged 8 to 16 years with HbAlc $>8 \%$, and verified that these patients also exhibited a higher level of glucose concentration in their saliva. Studies that compare caries prevalence in individuals with TIDM and a control group are controversial. Some have reported higher dental caries prevalence in individuals with TIDM $(1,18,34)$ while others found higher dental caries prevalence in the control group $(4,11,12)$. These differences may be explained, in part, by a wide age range evaluated in one of the studies (individuals aged between 11 and 81 years) (11) and by the sample size (25 patients) in another study (12). Surprisingly, some authors found a higher dental caries frequency in the non-diabetic group $(10,15)$. It must be emphasized that one of these studies (15) was conducted in a population with high dental cavity prevalence.

Salivary flow acts as a protecting agent of oral health. Thus, a reduction in salivary flow may lead to an increased dental caries frequency as well as a higher risk for oral diseases. In the current study, we found a lower stimulated salivary flow rate in the groups with high mean HbAlc values. This finding was described by other authors $(1,15-17)$. However, not all of them demonstrated an association between salivary flow and metabolic control $(15,17)$. A possible explanation for those results may be the small amount of individuals in the sample (15) and the cutting points chosen for HbAlc values (<6.5\% and $\geq 6.5 \%$ ) (17).

In conclusion, the present study demonstrated that glycemic control had an influence on the oral health of children and adolescents with TIDM. Thus, an oral evaluation should be part of routine procedures in the assistance of children and adolescents with TIDM, and questions about hyposalivation symptoms and the salivary flow rate should be asked. Moreover, the dentist should be a part of the multidisciplinary team that assists individuals with TIDM. More studies involving 
the oral health of children and adolescents with TIDM must be endorsed and conducted.

Acknowledgements: the authors would like to express their thanks to all of the employees of the Pediatric Endocrinology Unity, HC-UFPR.

Disclosure: no potential conflict of interest relevant to this article was reported.

\section{REFERENCES}

1. Moore PA, Guggenheimer J, Etzel KR, Weyant RJ, OrchardT. Type 1 diabetes mellitus, xerostomia, and salivary flow rates. Oral Surg Oral Med Oral Pathol Oral Radiol Endod. 2001;92(3):281-91.

2. Moore PA, Zgibor JC, Dasanayake AP. Diabetes, a growing epidemic of all ages. JADA. 2003;134(10):115-55.

3. Löe H. Periodontal disease. The sixth complication of diabetes mellitus. Diabetes Care. 1993;16(1):329-34.

4. Lalla E, Chieng B, Lal S, Tokcker S, Greenberg D, Goland R, et al. Periodontal changes in children and adolescents with diabetes. Diabetes Care. 2006;29(2):295-99.

5. Xavier ACV, Silva IN, Costa FO, Corrêa DS. Periodontal status in children and adolescents with type 1 diabetes mellitus. Arq Bras Edocrinol Metab. 2009;53(3):348-54.

6. Orlando VA, Johnson LR, Wilson AR, Maahs DM, Wadwa RP, Bishop FK, et al. Oral health knowledge and behaviors among adolescents with type 1 diabetes. Int J Dentistry. 2010(2010):942124, 8 pages, doi:10.1155/2010/942124.

7. Luczaj-Cepowicz E, Marczuk-kolada G, Waszkiel D. Evaluation of periodontal status in young patients with insulin-dependent diabetes mellitus (type 1). Adv Med Sci. 2006;51 Suppl 1:134-7.

8. Siudikienè $J$, Machiulskienè $V$, Dobrovolskienè $R$, Nedzelskiène I. Oral hygiene in children with type I diabetes mellitus. Stomatologija. 2005;7(1):24-7.

9. Sollecito TP, Sullivan KE, Pinto A, Stewart J, Korostoff J. Systemic conditions associated with periodontitis in childhood and adolescence. A review of diagnostic possibilities. Med Oral Patol Oral Cir Bucal. 2005;10(2):142-50.

10. Orbak R, Simsek S, Orbak Z, Kavrut F, Colak M. the influence of type-1 diabetes mellitus on dentition and oral health in children and adolescents. Yonsei Med J. 2008;49(3):357-65.

11. Arrieta-Blanco JJ, Bartolomé-Villar B, Jiménez-Martinez E, Saavedra-Valejo P, Arrieta-Blanco FJ. Bucco-dental problems in patients with diabetes mellitus (I): index of plaque and dental caries. Med Oral. 2003;8(2):97-109.

12. Andrades KMR, Ávila LFC, Miguel LCM, Odebrecht MLR, Rosa EAR. Influence of glycemic control on the experience of caries and periodontal disease in type 1 diabetic patients. Arq Odontol. 2009; 45(3):147-53.

13. Busato IMS, Bittencourt MS, Machado MAN, Grégio AMT, Azevedo-Alanis LR. Association between metabolic control and oral health in adolescents with type 1 diabetes mellitus. Oral Surg Oral Med Oral Pathol Oral Radiol Endod. 2010;109 (3):e51-6.

14. Twetman S, Johansson I, Birkhed D, Nederfors T. Caries incidence in young type 1 diabetes mellitus patients in relation to metabolic control and caries-associated risk factors. Caries Res. 2002;36(1):31-5.

15. Siudikiene J, Machiulskiene V, Nyvad B, Tenovuo J, Nedzelskiene I. Dental caries and salivary status in children with type 1 diabetes mellitus, related to the metabolic control of the disease. Eur $\mathrm{J}$ Oral Sci. 2006;114(1):8-14.
16. Siudikiene J, Machiulskiene V, Nyvad B, Tenovuo J, Nedzelskiene I. Dental caries increments and related factors in children with type 1 diabetes mellitus. Caries Res. 2008;42(5):354-62.

17. Javed F, Sundin U, Altamash M, Klinge B, Egstrom P-E. Self-perceived oral health and salivary proteins in children with type 1 diabetes. J Oral Rehabil. 2009;36(1):39-44.

18. Busato IMS, Ignácio AS, Brancher JA, Moyses ST, Azevedo-Alanis LR. Impact of clinical status and salivary conditions on xerostomia and oral health-related quality of life of adolescents with type 1 diabetes mellitus. Community Dent Oral Epidemiol. 2012;40(1):62-9.

19. Lopez MA, Colloca ME, Páez RG, Schallmach JN, Koss MA, Chervonagura A. Salivary characteristics of diabetic children. Braz Dent J. 2003;14(1):26-31.

20. Zaitter S, Ferencz C, Tomazinho PH. Evaluation of salivary microbiota of pediatric patients with and without mellitus type 1 diabetes. Rev Sul-Bras Odontol. 2006;3(1)24-7.

21. Artheiam A, Omar S. Dental caries experience and periodontal treatment needs of 10- to 15-year old children with type 1 diabetes mellitus. Int Dent J. 2014;64(3):150-4.

22. International Diabetes Federation (IDF) Diabetes Prevalence. Available from: http:/www.idf.org/home/index.cfm. Accessed on: Jan 16. 2009.

23. Santana TD, Costa FO, Zenóbio EG. Impact of periodontal disease on quality of life for dentate diabetics. Cad Saude Publica. 2007;23(3):637-44.

24. Naughton MJ, Ruggiero AM, Lawrence JM, Imperatore G, Klingensmith GJ, Waitzfelder B, et al.; SEARCH for Diabetes in Youth Study Group. Health-related quality of life of children and adolescents with type 1 or type 2 diabetes mellitus: SEARCH for Diabetes in Youth Study. Arch Pediatr Adolesc Med. 2008;162(7):649-57.

25. Rigby AS. Statistical methods in epidemiology. v. Towards an understanding of the kappa coefficient. Disabil Rehabil. 2000;22(8):339-44.

26. Greene JC, Vermillion JR. The simplified oral hygiene index. J Am Dent Assoc. 1964; 68:7-13.

27. World Health Organization. Oral Health Surveys: Basic Methods. Geneva: World Health Organization; 1997.

28. Association of Public Health Epidemiologists of Ontário. deft/ DMFT index, 2004. Available from: http://www.apheo.ca/index. php?pid=154).

29. Amenábar JM, Pawlowski J, Hilgert J, Hugo FN, Bandeira DR, Lülher $F$, et al. Anxiety and salivary cortisol levels in patients with burning mouth syndrome: case-control study. Oral Surg Oral Med Oral Pathol Oral Radiol Endod. 2008;105(4):460-5.

30. Tenuovo J. Salivary parameters of relevance for assessing caries activity in individuals and populations. Community Dent Oral Epidemiol. 1997;25(1):82-6.

31. Austin PC, Tu JV. Automated variable selection methods for logistic regression produced unstable models for predicting acute myocardial infarction mortality. J Clin Epidemiol. 2004;57(11):1138-46.

32. Zanetti ML, Mendes IAC. Análise das dificuldades relacionadas às atividades diárias de crianças e adolescentes com diabetes mellitus tipo 1: depoimento de mães. Rev Latino-Am Enfermagem. 2001;9(6):25-30

33. Karjalainen KM, Knuuttila MLE. The onset of diabetes and poor metabolic control increases gingival bleeding in children and adolescents with insulin-dependent diabetes mellitus. J Clin Periodontol. 1996;23(12):1060-7.

34. Miralles L, Silvestre FJ, Hernandez-Mijares A, Bautista D, Llambes F, Grau D. Caries dental en diabéticos tipo 1: Influencia de factores sistémicos de la enfermedad en la instauración de la caries dental. Med Oral Patol Cir Bucal. 2006;11:E256-60. 